\title{
LAS SEMILLAS DEL CAMBIO. El arte como estrategia para crear conciencia ecológica
}

\author{
Pilar SOTO SÁNCHEZ \\ Universidad de Granada \\ pilarsotosanz@gmail.com
}

\section{SEEDS OF CHANGE. Art as a strategy to create ecology counsciuosness}

Resumen: Navegamos en una crisis titánica que afecta a todos los ámbitos que conforman la vida, una crisis que está destruyendo el planeta y sus ecosistemas y con ello a nosotros mismos. Desde mi perspectiva y sentimiento como artista, comprendo el arte como un instrumento de cambio de la situación desequilibrada que tenemos con la Tierra. El presente artículo trata sobre la necesidad de despertar una conciencia sobre el medioambiente para comenzar a realizar la transformación sociocultural que necesitamos y evitar, en la medida de lo posible, el naufragio al que nos dirigimos. En esta investigación se proponen las miradas y estrategias de ciertas prácticas artísticas comprometidas con el entorno y su sociedad como dispositivos de conexión con una conciencia ecológica. Una gran variedad de artistas desde los años sesenta hasta la actualidad han representado, denunciado o revisado la relación del ser humano con su entorno, activando nuevas formas de mirar y actuar sobre el espacio. La creatividad de la acción artística es capaz de hacer de puente conector entre individuo y Naturaleza. Este trabajo pretende visibilizar la habilidad transformadora interior y exterior de ciertas prácticas artísticas que, lanzando semillas en todas direcciones y lugares, son capaces de generar nuevos caminos hacia la sostenibilidad.

Abstract: We're navigating in a deep crisis that affects the entire life spheres, a crisis that is destroying our planet, its ecosystem and, at the same time, ourselves. From my point of view and my artist soul, I understand art as a resource to change the unbalanced situation of the Earth. This article is about the necessity to arise an environmental awareness to start with a sociocultural transformation and avoid, as much as possible, the wreck we're going through. In this research I propose exclusive visions and strategies chosen from artistic practices involved in the environment and in its society, as a connection devices to create ecology consciousness. Many different artists, from the 60s until now, represented, denounced or reviewed the relation existing among the human being and its environment, activating new ways to look at the space and to act on it. The creativity of the artistic action is able to be a bridge among individuals and Nature. The aim of the article is to give visibility to the interior and exterior transformation abilities of art that, throwing seeds in all directions and places, is able to generate new paths through sustainability.

Palabras clave: Arte. Naturaleza. Medioambiente. Conciencia. Ecología. Transformación. Sostenibilidad. Sociedad Art. Nature. Environment. Awareness. Ecology. Transformation. Sustainability. Society 


\title{
La grieta como oportunidad para dar espacio a la vida
}

\begin{abstract}
"Cuando alcanzamos los límites del planeta, todo parece volver a nosotros en una suerte de efecto bumerán ubicuo y multiforme, y se vuelve imperiosa la necesidad de organizar de una manera radicalmente distinta nuestra manera de habitarlo" (Riechamn,2005: 100).
\end{abstract}

El mundo ha ido evolucionando hacia la situación insostenible en la que actualmente nos encontramos. La sociedad capitalista que hemos creado ha destruido prácticamente todas las relaciones de respeto y equilibrio que un día tuvimos con la Tierra. Vivimos inmersos en la inercia de una sociedad tecnocientífica industrial que va de camino, cuesta abajo y sin frenos hacia el colapso. No existe el equilibrio, no importa a qué ámbito dirijamos la mirada todo está infectado, el caos reina.

Las consecuencias de nuestro comportamiento sobre el planeta tienen efectos nefastos para todos los seres vivos, generando lo que podríamos llamar: una crisis ecológico-social. La extracción descontrolada de recursos naturales, el agotamiento de las energías fósiles, la emisión de gases de efecto invernadero, la deforestación, el mal uso del suelo y la contaminación, entre otros procesos de origen antropogénico, son causas que derivan en efectos a nivel planetario y éstos a su vez originan otras situaciones que aumentan el desequilibrio. El calentamiento climático, la extinción de las especies, la pérdida de biodiversidad, las crisis económicas y sociales, los conflictos, las guerras, la violencia, los refugiados, la pobreza, las injusticias; todo está interconectado, hemos entrado en un bucle destructivo de comportamiento caótico.

Es necesario como especie comprender que la vida humana depende de la salud del planeta, que nuestra situación finita es igual que la de la Tierra, que precisamos de ciclos vitales como ella y que necesitamos cuidarnos y cuidarla a ella para sobrevivir como especie. Esto nos hace ser seres interdependientes y ecodependientes por naturaleza, lo cual nos une de una manera absoluta a la Tierra.

No podemos negar que, tal y como lo denomina y anuncia reiteradamente el escritor y filósofo ecologista Jorge Riechmann desde 2013, estamos en -El Siglo de la Gran Prueba-, durante el cual debemos ajustarnos a los límites biofísicos del planeta si queremos sobrevivir al ecocidio al que nos dirigimos a gran velocidad. Ahora más que nunca tenemos los conocimientos necesarios para saber que este ajuste es imprescindible para afrontar la crisis ecológico-social. Aunque parezca demasiado tarde es mejor agarrarse a aquel dicho "más vale tarde que nunca" e iniciar a poner frenos para desacelerar el ritmo y cambiar el rumbo.

Necesitaríamos un nuevo comenzar conscientes de lo aprendido y de lo pasado, actuado en el presente y proyectando hacia el futuro. Es cierto que todo está antropizado y comenzar de cero sería como intentar separar la leche del café después de mezclarlo en nuestra taza. Desafortunadamente, no podemos regresar al pasado y no echarle leche al café, pero afortunadamente si podemos comenzar a tomar café solo desde hoy mismo. Podemos pues originar nuevas inercias que nos lleven a lo que podría ser un nuevo renacer.

Bajo este panorama tenemos dos opciones de cambio: el colapso o el modelo de revolución. Uno consistiría en hacer lo que hemos estado haciendo hasta ahora, dejándonos llevar con la inercia dominante que hemos creado de caos, esperando que el equilibrio llegue a quienes queden sobre la Tierra después de sufrir el colapso y la catástrofe; y la otra opción es la de ir contra la inercia, apostando por un modelo revolucionario y pacifico de iniciativas que generen soluciones activas y escenarios para transición hacia un futuro sostenible.

Desde una reflexión positivista: que la humanidad, con la inercia hegemónica que actualmente lleva, sea capaz de realizar una revolución de tal calibre, es una misión improbable 
pero no es imposible. Debemos transformarnos en sociedades biomiméticas, convertir nuestros sistemas culturales de alta entropía en sistemas de baja entropía, sociedades que en su renacer permitan la subsistencia en la Tierra en una relación equilibrada con la Naturaleza.

El cambio hacia sociedades de baja entropía debe generarse desde una visión holística. Estamos ante una Naturaleza totalmente desprotegida que ha sobrevivido hasta hoy bajo una ética equivocada. Las reglas morales de la ética tradicional se han ocupado de dar razón a las obligaciones morales de los seres humanos y para los seres humanos, olvidando la totalidad de la vida. Y a pesar de que en la ética existen enfoques de conciencia ecológica que han dado protección y relevancia moral a la naturaleza, no ha sido suficiente su fuerza y se han mantenido siempre al margen de un sistema capitalista al que no le conviene cuidar la Tierra, puesto que su objetivo es consumirla.

Las respuestas al impacto de la crisis ecológica dependen de un cambio de paradigma profundo en nuestra concepción del mundo y la Naturaleza, un cambio en la cosmovisión que conlleve una ética y una praxis adecuada para el equilibrio de nuestra convivencia con la Tierra, un cambio de consciencia. Afortunadamente, en la actualidad y cada vez con mas fuerza, se está cuestionando la necesidad del cambio, no solo por salvar lo que queda de Naturaleza, de biodiversidad, de recursos o de ecosistemas, si no también por nuestra propia duración como especie en este planeta. Quizás el miedo a nuestra propia extinción sea lo único que nos haga despertar la consciencia ecológica y apostar por un modelo revolucionario de cambio hacia la sostenibilidad.

Es cierto que el problema es titánico y que reside en la estructura defectuosa de nuestros sistemas llegando a contaminar nuestras consciencias. También es cierto que es difícil de moderar, pero no es imposible. Podemos comenzar desde la base, desde lo local, desde lo pequeño, desde la grieta como oportunidad para dar espacio a la vida. Desde la semilla cargada de vida que aún queda en nosotros y que poco a poco puede enraizar dentro y ascender en el exterior ramificándose hacia todas las direcciones para dar fruto a una nueva consciencia en equilibrio con la Naturaleza, con la vida.

\section{Reflexiones sobre la consciencia ecológica}

¿Cómo es posible que desde los años cincuenta y sesenta que comenzaron las serias advertencias sobre el deterioro del medioambiente, aún sigamos ciegos y sordos antes una situación que empeora a gran velocidad? Como hemos visto, el arranque de un tiempo de visibilización de las problemáticas y de concienciación ecológica comenzó hace mucho tiempo y sigue latente con luchas desde diferentes ámbitos y con estrategias de toda clase. El problema se conoce y todos hemos escuchado hablar de la:

"consciencia ecológica", pero parece que aún no ha llegado a afectarnos emocionalmente a nivel global y que solo algunos grupos de personas han llegado a captar la urgencia. Esto nos da la sensación de que podemos encontrar más teoría que acción en esta misión por despertar. Como apunta Tonia Raquejo, “ [...] parece pues que la consciencia ecológica no ha llegado a desarrollarse a pesar de estar ya incrustada en el lenguaje [...]" (Raquejo: 2015: 68)

Existen testimonios influyentes que nos han recordado siempre las tempranas advertencias sobre la necesidad de frenar y comenzar a actuar desde una consciencia ecológica. Hablando de mujeres que han cambiado la percepción del mundo, encontramos los escritos de la bióloga Rachel Carson que ya en 1962, con su libro "Primavera Silenciosa"(fig.1), llegó a originar un impacto fuerte en la conciencia pública y despertó un activismo medioambiental a nivel mundial. Un libro que inspiró a muchas personas y movimientos e hizo historia 

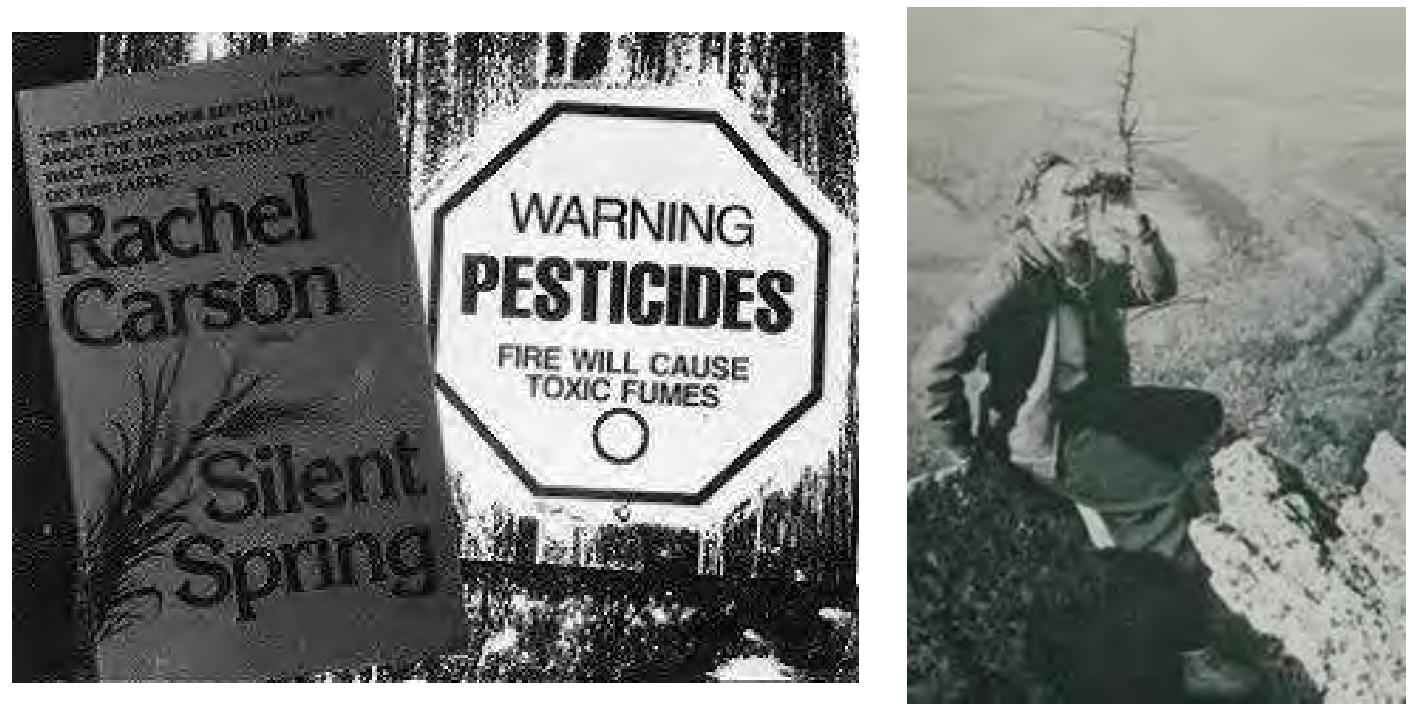

Figura 1: Rachel Carlson y su libro Primavera Silenciosa, 1962: http://explorepahistory.com/ displayimage.php?imgId=1-2-449

intentando alterar la dirección del pensamiento y las acciones de la humanidad sobre el medioambiente.

Si reflexionamos sobre la cantidad de escritos y efectos visibles que se han sacado a la luz, como se puede comprobar desde los años sesenta hasta la actualidad, nos damos cuenta que no somos capaces de atender a las voces de alerta ni estamos preparados para asumir la realidad. A pesar de tener la capacidad cognitiva de percibir ¿Qué es lo nos hace no ser conscientes?.

\title{
¿Qué es lo que tenemos desconectado?
}

\begin{abstract}
“[...] La Naturaleza,...la entenderemos como un proceso dinámico que se proyecta tanto en un ámbito cósmico como cuántico, siendo generadora de la materia y transformadora de la energía y la vida, de la cual formamos parte y, por tanto, dependemos primariamente para ser y subsistir, si bien su horizonte trasciende con mucho la existencia de nuestra especie" ( Raquejo: 201: 167).
\end{abstract}

Está claro que Naturaleza somos también nosotros y parece increíble que a estas alturas aún no seamos conscientes. No hay equilibrio entre nuestros actos con el medioambiente y la consecuencia de estos sobre el planeta. La cuestión no comienza en el desequilibrio: el problema radica en la desconexión consciente que existe entre nuestras acciones y la de repercusión de éstas. Entonces, ¿qué es lo que hay desconectado para que no lleguemos a ser conscientes?

Con respecto a esto, Jane Goodall nos insinúa que el problema está en una desconexión entre el cerebro y el corazón. A continuación reproduzco textualmente una parte del discurso que Goodall realizó en “TED conferences” en 2007:

...aquí estamos nosotros, probablemente el ser mas inteligente que jamás haya caminado sobre el planeta Tierra, con ese cerebro extraordinario, capaz del tipo de tecnología [...] y aún así estamos destruyendo el único hogar que 
tenemos. [...] Los indígenas alrededor del mundo, antes de tomar una decisión importante, se sentaban y preguntaban, ¿Cómo afectará esta decisión a nuestra gente dentro de siete generaciones? Hoy en día, las grandes decisiones del mundo desarrollado, las grandes decisiones que involucran millones de dólares y millones de personas, suelen basarse en, ¿cómo afectará ésta a la próxima reunión de accionistas? [...] Parece que hemos perdido la sabiduría, la sabiduría de los pueblos indígenas...¿Por qué? ¿Creen que puede haber algo desconectado entre este cerebro extraordinariamente inteligente y el corazón humano? Hablando de ello en una forma no científica. En términos del amor y compasión, ¿hay algo desconectado? (Jane Goodall: 2007).

Goodall nos recuerda, con estas palabras, que existe la capacidad del ser humano para alejar la egocentricidad y empatizar con el mundo y con todos los seres que le rodean. Esta parece ser una capacidad que solo ha quedado intacta en ciertas sociedades indígenas, las cuales han mantenido una relación equilibrada con la Naturaleza.

La empatía tiene mucho que ver con una respuesta afectiva a la percepción, un razonamiento que pasa por la emoción de un sentimiento producido por lo percibido. Al contrario, en el individuo actual de la sociedad moderna industrializada, no parecen existir grandes dosis de esa empatía y menos la empatía que tiene que ver con todo lo que se refiere a la interiorización del estado de crisis ecológico en el que vivimos.

Nuestra capacidad de transformarnos en seres empáticos está contaminada por el sistema capitalista que hemos creado. En esta sociedad moderna, el funcionamiento de la razón parece contrario a la capacidad de sentir y activar la empatía necesaria para encontrar el equilibrio. La capacidad de destruir lo que nos da la vida es evidentemente contradictoria. Sobre esta contradicción Raquejo, en su texto nos dice que "la ficción en la construcción de la conciencia ecológica: correspondencias entre las dinámicas psíquicas y el planeta tierra", recuerda esta fragmentación mental con la que "[...] somos capaces de devorar nuestro hábitat ecológico al tiempo que investigamos y exploramos las nefastas consecuencias de ello sin apenas conflicto". (Raquejo: 2015: 68)

\section{Interferencias. La contaminación del "Yo analógico"}

Las interferencias creadas en el exterior han contaminado nuestro interior y, en esta confusión, parece que ya no existe el diálogo entre la razón y la emoción. Estamos desconectados de nuestras raíces naturales, olvidamos que somos Naturaleza y poco a poco nos convertimos en artificio. Nos conformamos conviviendo con trozos de naturaleza artificiales que se disponen en nuestro entorno urbano como mera decoración, ornamentos que hacen frivolizar nuestra primigenia conexión con la Naturaleza, espacios "naturales" encerrados en una jungla de hormigón.

Esta interrupción de la conexión entre la Naturaleza interior y exterior, nos lleva a una pérdida de control de la conciencia; hemos perdido el equilibrio, actuamos contra la Naturaleza y por ello contra nosotros mismos. No somos capaces de percibirnos en el mundo como seres que han nacido de la Tierra, seres con capacidad para relacionarse conscientemente con el medioambiente.

La consciencia es una capacidad de la mente con la que el ser humano experimenta el reconocimiento interior de aquello que le circunda y lo relaciona con él mismo, con su "yo interior", dimensión al que Tonia Raquejo (2015), retomando las teorías de la mente bicameral de Julian Jaynes, nombra como el "yo analógico". "La consciencia surge cuando esta mente bicameral interconecta sus espacios, lo que genera un mundo analógico al real que se construye con léxico, metáforas y analogías del comportamiento -vivencias- del mundo físico". (Raquejo: 2015: 61). 
Según Jaynes la mente del ser humano está dividida en dos espacios conexos, siendo en el funcionamiento de esa interconexión cuando surge la conciencia, que se sitúa en un espacio mental analógico. Es por lo tanto en ese espacio donde se alberga el "yo analógico", donde nos vemos y somos conscientes de vernos. (Raquejo: 2015: 61-62).

Pensar en esa capacidad de la mente y en la existencia de ese espacio analógico donde se alberga el "yo consciente", podría significar que somos capaces de reconstruirnos interiormente, siendo conscientes del exterior. En ese lugar donde "nos vemos", no nos imaginamos flotantes en una especie de "nada", puesto que no somos nada sin el medio donde vivimos. Por lo tanto nos reconstruimos analógicamente con nuestro entorno; pero ¿qué entorno reconstruimos?, ¿dónde nos vemos conscientes?.

Si somos capaces de ver nuestro "yo analógico" en el medio físico que nos rodea y éste normalmente es la ciudad y todo el sistema que ella conlleva, entonces no podremos ser conscientes de la Naturaleza y su medioambiente, puesto que esto es prácticamente inexistente y lo poco que queda de ello en las ciudades es una construcción humana artificial que atraviesa el umbral del equilibrio. Algunos autores que han estudiado tanto la concepción de "Naturaleza" como su terminología (Albelda y Saborit: 1997; Raquejo: 2013), nos ofrecen una visión más profunda sobre el binomio naturaleza-artificio.

Quizás la respuesta a la falta de consciencia medioambiental deriva simplemente del hecho de que no vivimos con la Naturaleza, si no de ella y que la utilizamos pero no la entendemos, la consumimos pero no convivimos.

¿Cómo pretendemos entonces tener una conciencia ecológica si los escenarios y los modos de vida en los que estamos sumergidos no tienen nada que ver con la Naturaleza, su biosfera y sus ritmos?

\section{El despertar del "yo ecológico"}

Explorar nuestras respuestas internas tras la percepción de nuestro mundo supone la extensión del "Yo". Identificarnos con el entorno y con todos los seres vivos, humanos y no humanos nos hace despertar y fortalecer el vínculo que tenemos con la Tierra. La observación y experimentación profunda de la Naturaleza en todas sus formas supone ensanchar las fronteras del "Yo", aumentando la empatía con todo lo vivo y llegando a transformar ese "yo individual y egoísta" en un "yo compartido y colectivo". Esta evolución supone el desarrollo de lo que Arne Naess en 1995, denomina como "yo ecológico". (Iglesias: 2009)

Hemos ido involucionando en nuestro entorno transformándolo en un espacio hostil que nada tiene que ver con la Naturaleza, ni con la vida en sus orígenes, puesto que si vivimos entre asfalto, edificios y plásticos y nos vestimos y comemos petróleo, químicos y tóxicos, entonces parece que "Nuestras raíces están en la urbe, no en la tierra"(Carandell: 2015: 29). Bajo este panorama ¿cómo podemos obtener la consciencia del "yo ecológico"?, ¿quizás la falta de consciencia que tenemos sobre el medioambiente sea simplemente por la falta de conexión física con este?.

Quizás solo somos capaces de imaginarnos conscientemente rodeados de edificios, de cemento, de ciudades con modos de vida consumistas y dominantes. Entonces, si somos urbanitas enraizados en el asfalto y vivimos ignorando qué es lo que nos da la vida, ¿podríamos aún despertar esa conciencia del "yo compartido" a través del contacto con la Naturaleza y la comprensión de sus procesos y funcionamiento?

Volviendo a reflexionar sobre el funcionamiento de la mente bicameral y sobre la falta de conexión del "yo analógico" en su "verse" en el medioambiente, parece que algo falla. Me atrevo a decir que la consciencia dormida puede ser un estado patológico de la mente del ser humano, construido por la sociedad moderna industrializada, la cual ha creado individuos desnaturalizados, incapaces de verse y sentirse parte de la Naturaleza.

Somos seres con una conciencia incompleta, fragmentada o enferma, una consciencia 
que no se rige por conexiones en armonía con la Naturaleza, sino por conexiones que nacen del egoísmo y del egocentrismo de un "yo analógico" enraizado en la urbe y en una sociedad moderna industrializada, la cual anula a la Naturaleza haciendo dormir una parte de nuestra consciencia y alejándonos del "yo ecológico".

No todo está perdido y lo más importante es ser optimistas, pero no un optimismo ignorante, si no uno constructivo que se apoye en la realidad para trascender con la ilusión de un nuevo comenzar. Debemos agarrarnos a lo que Riechmann denomina "La militancia de la alegría" (Riechmann,2015: 261). Puesto que aún seguimos siendo Naturaleza y prescindimos de ella, aún estamos a tiempo de modificar formas de hacer y valores, capaces de hacernos despertar ese "yo compartido".

El reflejo de nuestro interior es una mirada hacia el exterior, pero esta dualidad entre lo reflejado y el reflejo puede modificarse con una visión única de ambas. Si comprendemos que somos lo que hacemos y vemos, seremos capaces de conectar con el "yo ecológico" para llevarnos a respetar el medio natural, pero lo más difícil es averiguar cómo vamos a realizar esa conexión interna capaz de tener una relación equilibrada con el entorno. Y es aquí donde necesitamos el pensamiento creativo que las artes pueden ofrecernos para construir nuevos imaginarios, capaz de fomentar conciencias alternativas a las reflejadas por el sistema capitalista.

Existen diversos estudios que defienden la capacidad del arte como dispositivo de conexión y actualmente están germinando cada vez más prácticas artísticas que mantienen esa concentración por un cambio de consciencia hacia el despertar del "yo ecológico". El arte puede ser el espejo que interviene entre el reflejo y lo reflejado, entre el interior y el exterior, entre individuo y Naturaleza.

Desde la exposición de ciertas prácticas artísticas, mostraré, a continuación, el poder que éstas tienen para proponer soluciones creativas a las problemáticas actuales medioambientales. Demostraré también el potencial que tienen para cambiar la mirada, transformándose en el dispositivo que desactive la desconexión individuo-naturaleza y active la conciencia hacia un "yo ecológico".

\section{El arte como reactivador de la consciencia ecológica.}

Si es cierto que como dijo Carl Sagan "somos polvo de estrellas", entonces me atreveré a defender que la conexión que tenemos con todo el universo no ha desaparecido, sino que permanece intrínseca en nosotros y que la consciencia de esta conexión está dormida y la hemos hecho desaparecer.

Dentro de nosotros aún sigue codificada la memoria de ser parte del cosmos y de cada elemento que compone la vida, de la Naturaleza. Por lo que, si en lo más profundo de nuestro ser como materia o como energía quedó grabada la pertenencia del origen de la vida, entonces es ahí donde tenemos que conectarnos para darnos cuenta que nos hemos alejado de ella y que aún estamos a tiempo de corregir el rumbo.

Encuentro un amplio panorama de soluciones que la praxis artística es capaz de activar en diversos planos de nuestra realidad. Desde la conexión simbólica que transforma nuestro interior, tocando nuestro imaginario y dirigiéndose directamente a nuestro "yo ecológico", hasta la conexión práctica de consciencia medioambiental que interviene en el entorno con el fin de activar nuestra empatía.

Por lo tanto, individualmente o colectivamente como individuos, ciertos modos que tenemos de actuar y relacionarnos en/con el medio, son capaces de mostrar el rumbo hacia el cambio para la toma de consciencia. Refiriéndome como medio tanto al conjunto de circunstancias físicas que forman el espacio donde se desenvuelve la vida, como a el conjunto de normas políticas, sociales y culturales que nos construyen psicológicamente y moldean la fisicidad del espacio. 
El arte es un campo simbólico necesario para el ser humano, puesto que es una herramienta con la que el individuo es capaz de trascender para comunicar sus emociones y pensamientos. Es un lenguaje imprescindible para expresar y compartir estados conscientes e inconscientes del ser humano. Es capaz de crear nuevos dialectos, de promover interconexiones entre individuos y espacio, de ampliar el imaginario de las personas. Puede recrear escenarios de futuro y de pasado y es capaz de mostrar el presente desde la forma más poética y metafórica, hasta la forma más realista y rigurosa.

Encontramos personas y colectivos que llegan del "mundo del arte" para lanzar semillas que germinan en nuestras conciencias, activando nuestra sensibilidad y promoviendo el cambio en el exterior.

Si activamos este ciclo de cambio, será un bucle de eterno retorno (fig.2), puesto que una vez creada la consciencia hacia el interior, otros podrán activar soluciones, igual que aquellos que en el exterior comienzan activado soluciones, crearán una consciencia interior desde la práctica.

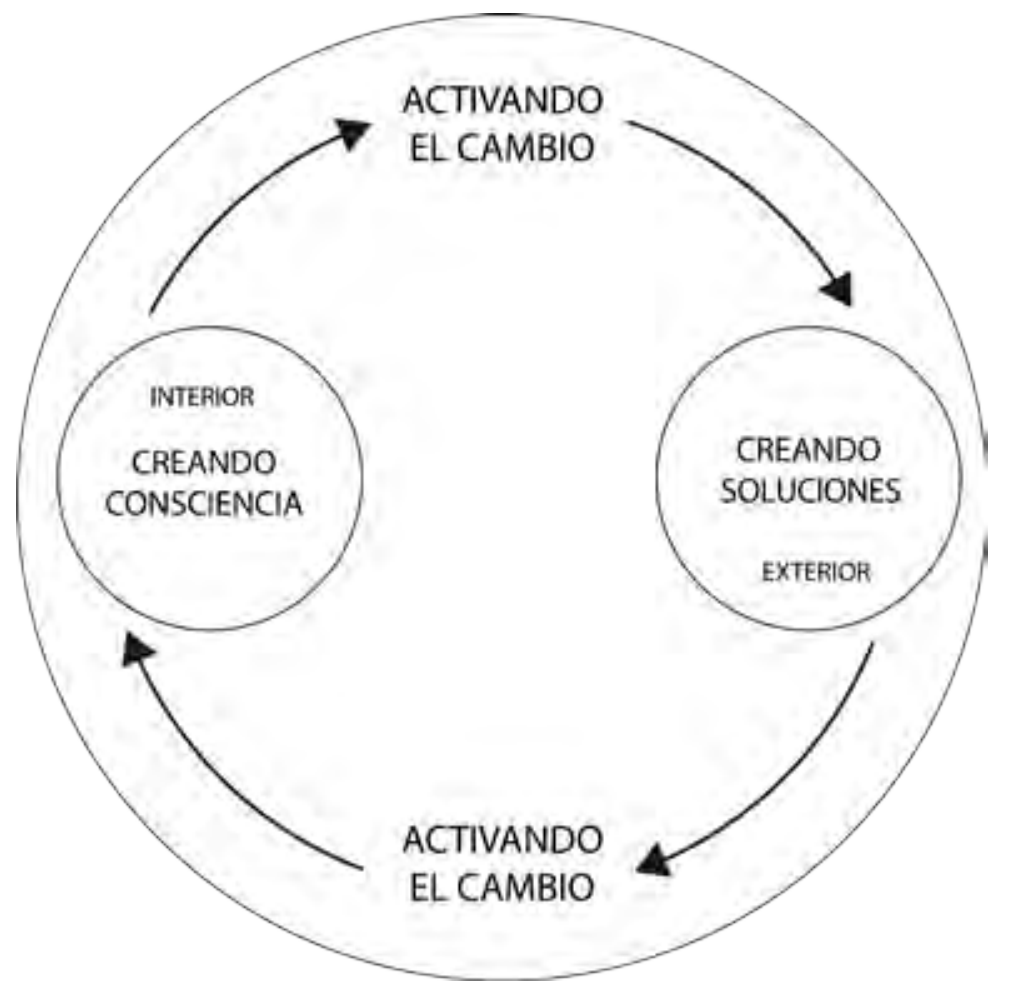

Figura 2: Mapa conceptual: Bucle de eterno retorno para la transformación desde el arte, 2015: realizado por la autora.

\section{Semillas de conexión desde la praxis artística}

Algunas prácticas artísticas portan la semilla para la transición y éstas normalmente germinan en lugares que no están destinados, en un principio, para el mundo del arte. Desde los años sesenta del siglo pasado algunos artistas comenzaron a desarrollar en gran parte la evolución del pensamiento ecologista, salieron de sus estudios y galerías para trabajar con la Naturaleza y por su medio ambiente. Actualmente la situación con el planeta sigue pendiendo de un hilo y tales iniciativas se han multiplicado. Hasta la fecha una gran variedad de prácticas artísticas siguen trascendiendo de la "caja blanca" para ampliar nuestra visión y reactivar el espacio público ofreciendo lugares de oportunidad y experimentación 
desde los que reflexionar sobre nuestra relación con el medio. A continuación hablaré de territorios fértiles para crear una consciencia ecológica desde el arte, de aquellos lugares de oportunidad que son imprescindibles para reinventarnos ante el panorama actual de crisis socio-ambiental.

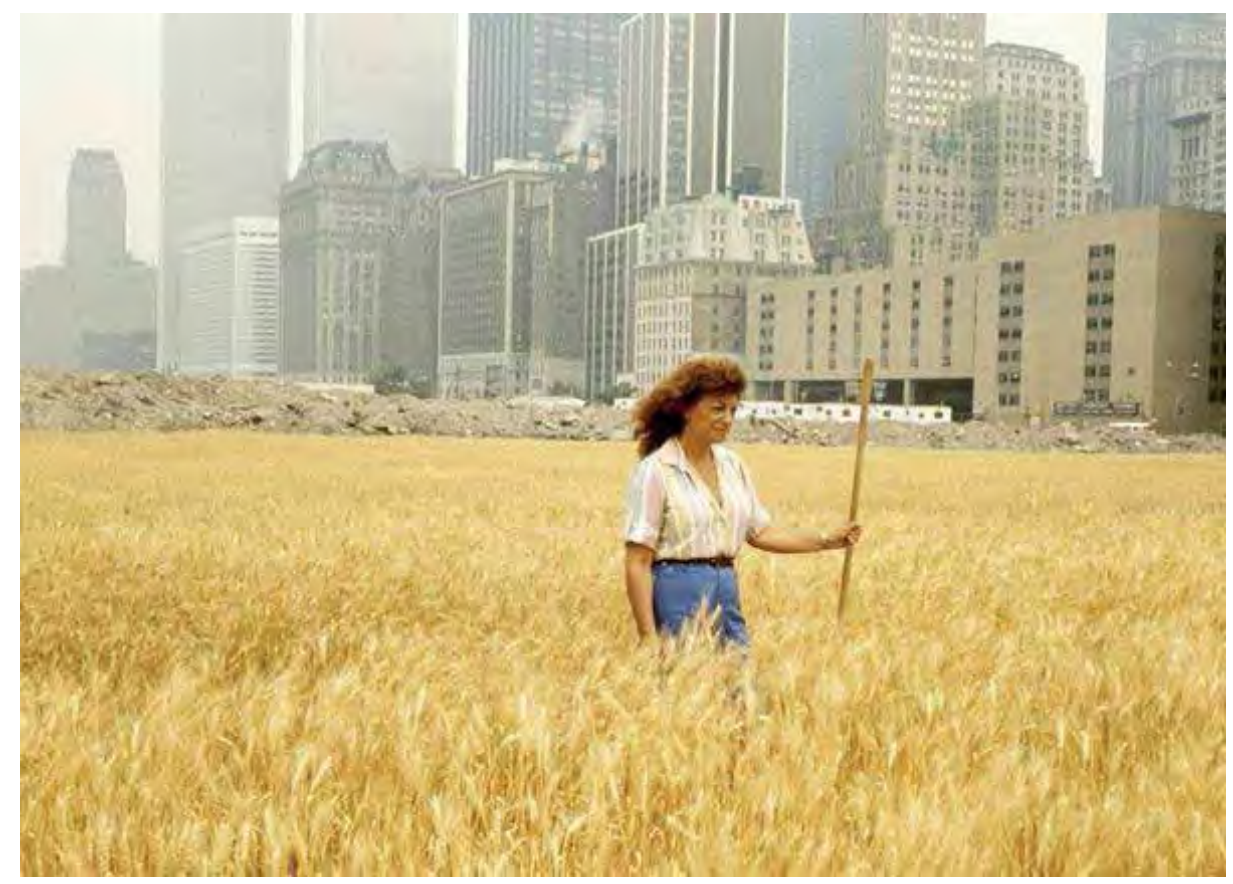

Figura 3: Agnes Denes, Wheatfield a Confrontation,1982:http://greenmuseum.org/c/aen/Images/Ecology/wheatfield.php

En la observación de las actividades de algunos artistas que han trabajado desde una ética ecológica con un compromiso político y social, encuentro que coinciden en la reutilización de ciertos lugares para la creación. Muchos de estos espacios forman parte de lo que el filósofo arquitecto Ignasi de Solà-Morales denominó con el término francés "Terrain Vague" ( Solà-Morales: 1996: 10-23). Solà propone este termino para definir aquellas áreas abandonadas, espacios y edificios obsoletos e improductivos, a menudo indefinidos y sin límites determinados. Son áreas en desuso que, en la mayoría de las ocasiones, han quedado en el limbo de la especulación inmobiliaria. Los "vacíos" de la ciudad, espacios de respiro y de vida, son y serán lugares fértiles para las semillas de un nuevo paradigma.

Podemos encontrar iniciativas muy tempranas en estos territorios, como consecuencia del despertar de la conciencia ecológica en algunos artistas. Como ejemplo encontramos al pionero Alan Sonfist, con su intervención "Time Landscape" (1965), con la cual convierte una zona inutilizada de la ciudad de Manhattan en un bosque de vegetación autóctona. Un proyecto que consistió en plantar, sobre un solar abandonado y lleno de escombros, un bosque en miniatura cuya vegetación se correspondía con la vegetación de Nueva York en época precolonial.

Unos años más tarde, en la misma ciudad, la artista Agnes Denes realizó por primera vez "Wheatfield A Confrontation" (1982) (fig.3). Reactivó un solar utilizado como vertedero ilegal en Manhattan, donde plantó en 0'8 hectáreas un campo de trigo. Para ello la artista limpió el territorio de basuras y escombros, creó surcos, implantó un sistema de regado e hizo la plantación. Treinta años más tarde, en 2015, Agnes Denes interviene en una isla de 
tierra que queda en medio de una zona de nuevos rascacielos en el corazón de la ciudad de Milán (fig.4). Después del fuerte impacto ambiental de estas monstruosas construcciones, Agnes repite Wheatfield en 5 hectáreas, pero esta vez la artista invita a colaborar a los vecinos de la zona a plantar las primeras semillas, lo que se convirtió en una obra colectiva con la gente local.

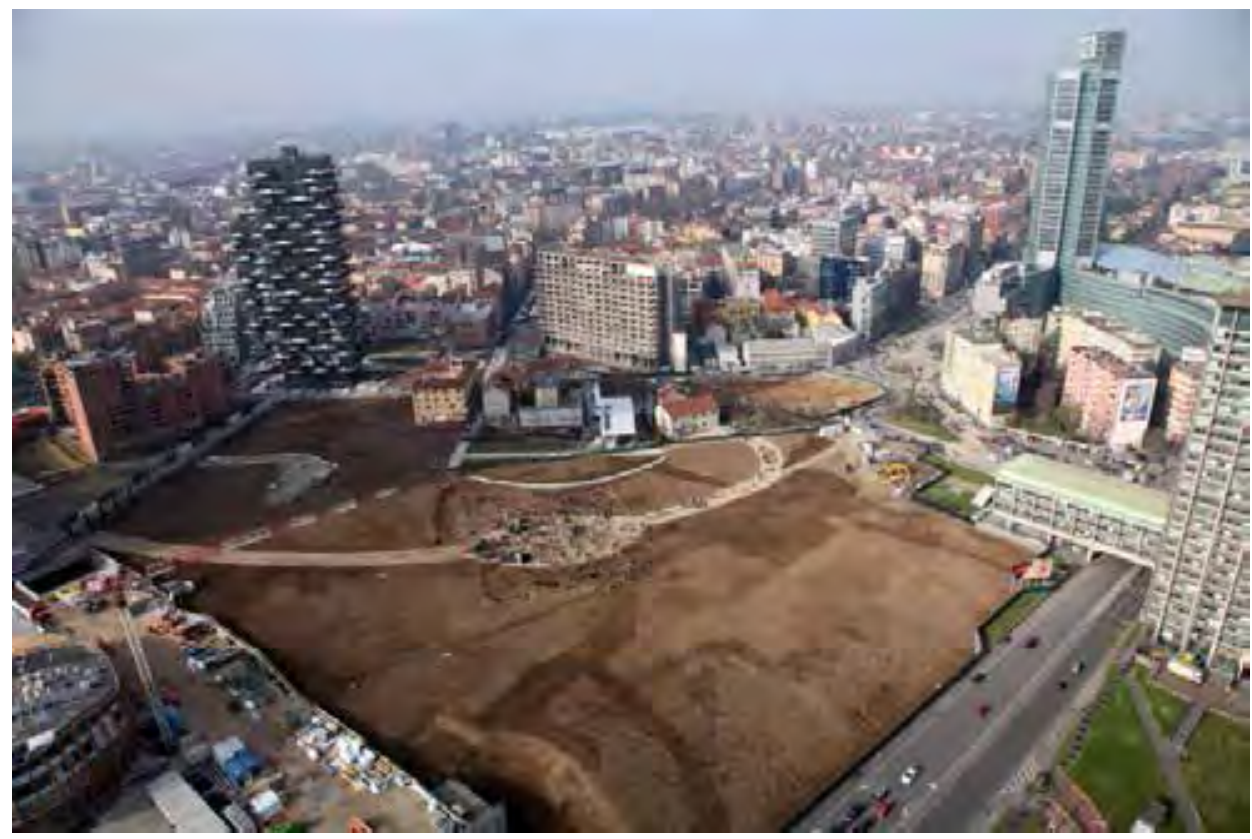

Figura 4:Agnes Denes, Wheatfield a Confrontation, 2015: http://www.strataproject.org/blog/ category/all

La reutilización, efímera o permanente y con fines ecosociales, de "espacios vacíos" en la ciudad, es una práctica actualmente en auge. Existen diferentes formas de actuación para transformar estos espacios en lugares para el florecimiento de la creatividad y del contacto con la Tierra. Esta reutilización de los "espacios de respiro" de la ciudad es utilizada por modos eco-sostenibles de ocupación del espacio, convirtiéndose en propuestas de educación ambiental que parten de la reactivación de una zona común para retomar contacto con la tierra. Uno de los modos más usados para la reactivación es a través de la creación de huertos urbanos, también conocido como movimiento de "Urban Gardening". Ejemplo de ello podemos encontrar en nuestro país el proyecto "Esto es una plaza" en el barrio de Lavapiés, Madrid.(fig.5)

Por otra parte, como contestación desde la práctica artística a los bosques de cemento, podemos recordar acciones como las de Khateryn Miller con "Seed bombs"(1991-2002) (fig.6). Miller realiza bolas de arcilla que contienen semillas, para lanzarlas por espacios de la ciudad, recogiendo, de este modo, la técnica de plantación de agricultura natural que creó y utilizó el maestro japonés Fukuoka desde 1975: "Se abandona en cierto modo la utilización de uso agrícola, pero de alguna manera se salva uno de los conceptos básicos de la filosofía de Fukuoka, comenzar la revolución con una brizna de paja [...]" (Soler y Soto: 2014: 329)

Un referente que critica y denuncia el avance de la sociedad moderna en la destrucción de los espacios y recursos naturales es Lois Weinberger. De una forma poética y política interviene en el espacio público para crear una conciencia medioambiental. Intenta concienciar a la sociedad sobre la importancia de la existencia de espacios naturales y la necesidad 


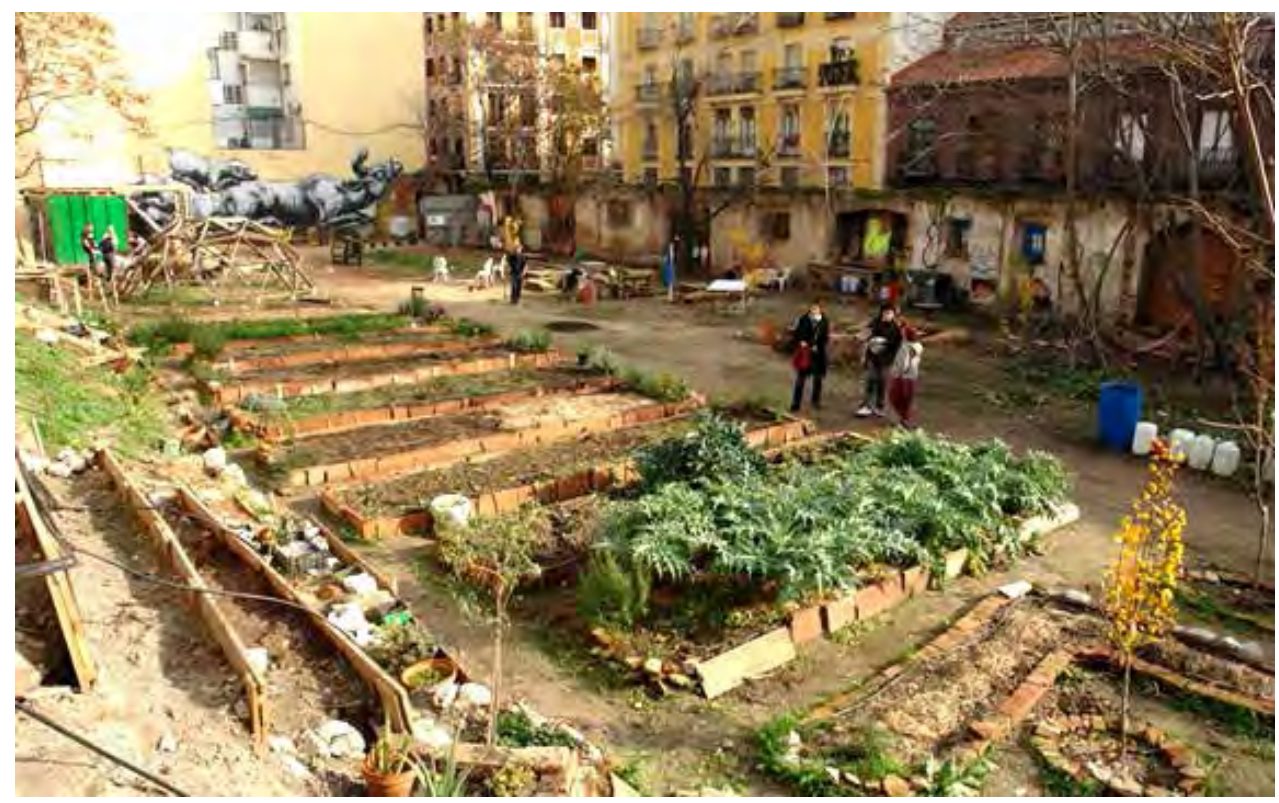

Figura 5: Esta es una plaza, Lavapiés, Madrid, 2008: http://estaesunaplaza.blogspot.com.es/

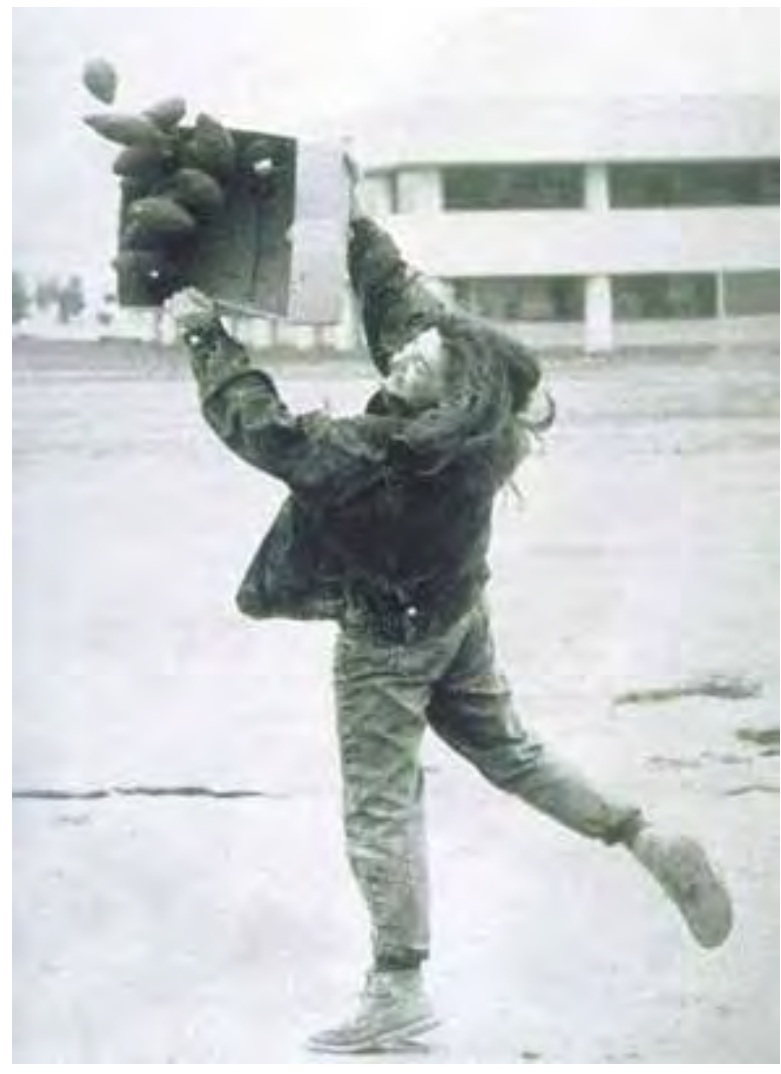

Figura 6: Khateryn Miller, Seed Bombs, 1991-2002: http://www.kathrynamiller.com/seedbombs.html 
de preservarlos. Una de las acciones de Weinberger, consiste en realizar rupturas en el asfalto en forma no organizada para después repartir semillas de vegetación autóctona entre los escombros. Las plantas germinan en las grietas del pavimento y la grieta se transforma en una oportunidad para la vida. (fig.7)

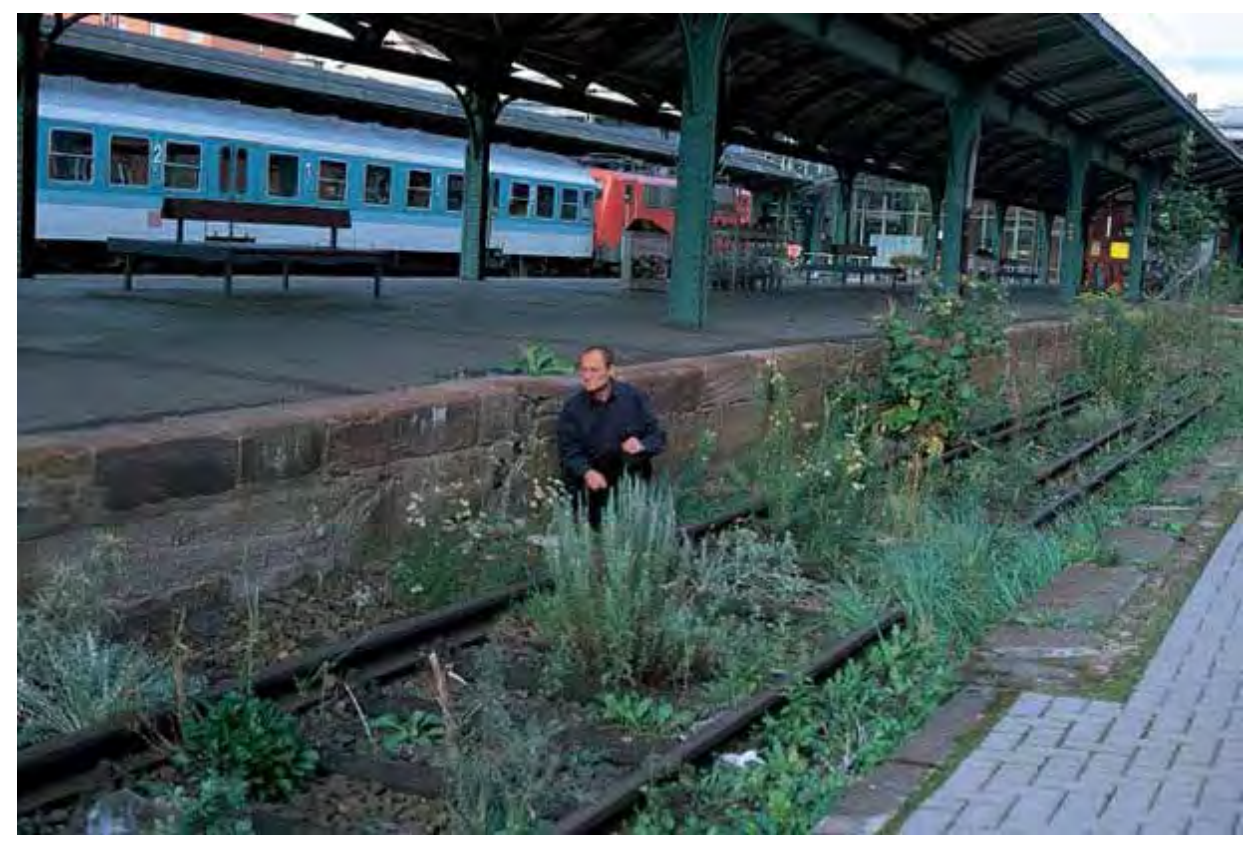

Figura 7: Lois Weinberger, Sin título, lanzamiento de semillas en Kassel,1997: http://www. loisweinberger.net/index.html\#Top

Las acciones de Weinberger atraen la mirada hacia los bordes, consigue hacer visible lo invisible a nuestra mirada urbanita y da la voz a una Naturaleza silenciosa que brota entre las condiciones más hostiles. Él trabaja en muchas ocasiones junto a su esposa Franziska y juntos reforestan poéticamente cualquier rincón desapercibido de la ciudad. Weinberger es un artista que ha intervenido sobre espacios que no están sometidos a la acción controladora del sistema urbano y los utiliza como una especie de "jardines salvajes".

Con Weinberger descubrimos que ya no solo son los "Terrain Vague" los posibles espacios de oportunidad, sino que éste se acerca más a los conceptos de "Tercer paisaje", de los que habla el arquitecto paisajista Guilles Clemènt (2007). Lugares que, por su "casi invisibilidad" tienen las características necesarias para que la vida evolucione espontánea.

Estos rincones a la sombra de nuestras ciudades, son estudiados por Clemènt en "El manifiesto del tercer paisaje". De forma poética y rigurosa, el arquitecto investiga sobre los territorios olvidados, espacios indecisos, desprovistos de función y les otorga la potencialidad de los espacios del futuro. El "Tercer paisaje" es aquel que resurge cuando el ser humano desaparece (Clemènt, 2007). La intencionalidad del manifiesto es invitar a la reflexión sobre estos territorios olvidados que se han convertido en refugios de la diversidad y la biodiversidad, espacios residuales cargados de emociones y vida. Volver la mirada a ellos desde la contemporaneidad supone ser conscientes de nuestros vacíos, de nuestra falta de consciencia y esta mirada, en los momentos actuales de crisis global, nos reactiva la creatividad para imaginar las posibilidades y la vida de esos lugares.

La artista Lara Almarcegui realiza acciones poéticas y políticas que reconocen lo no planificado y ponen en relieve la violencia de la erradicación de lo silvestre con la continua transformación y construcción arquitectónica de las ciudades. Como ejemplo de ello 


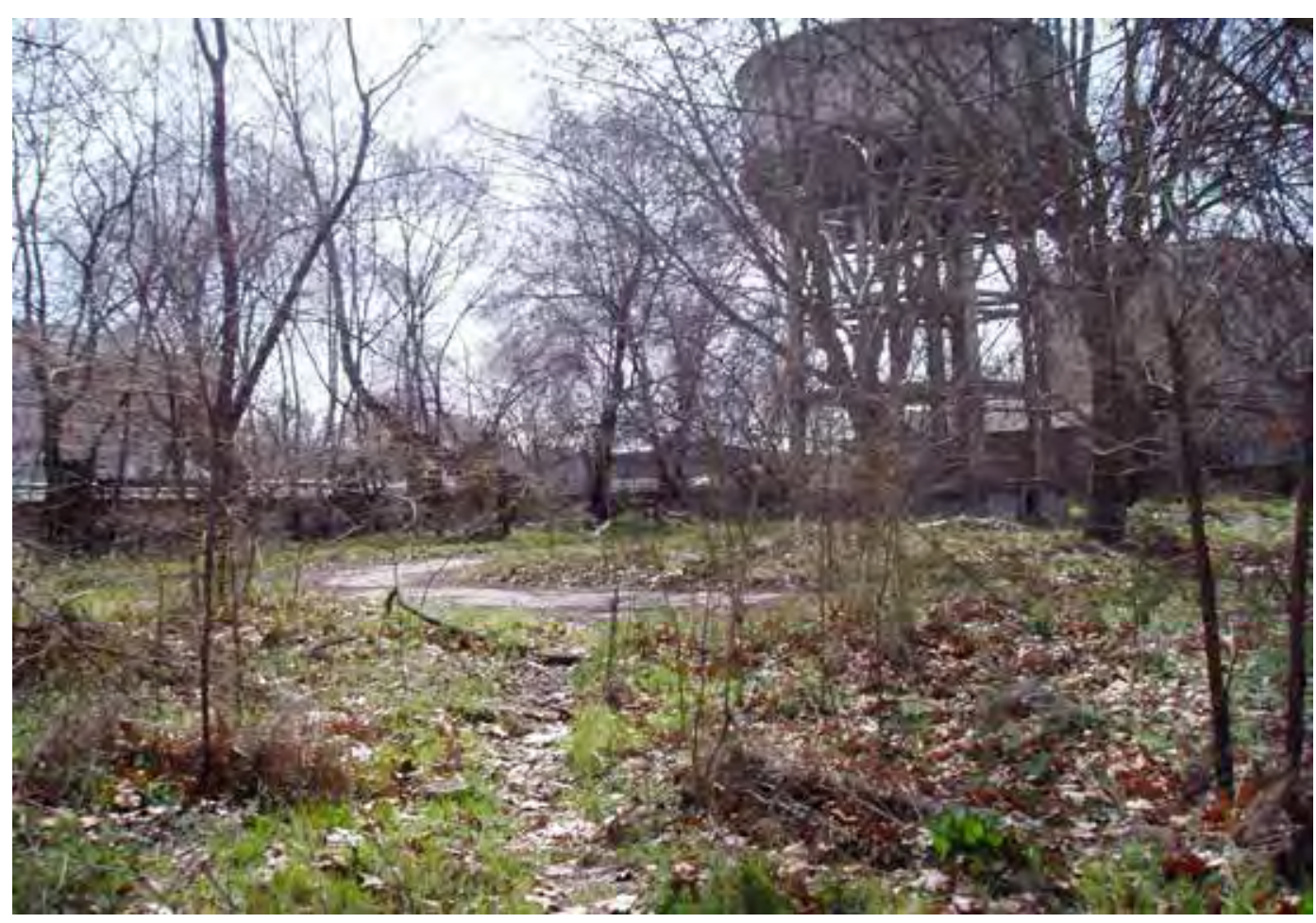

Figura 8: Lara Almarcegui, Un descampado, 2005-2006: http://www.ca2m.org/es/component/ phocagallery/category/173-lara-almarcegui?catid=category

podemos nombrar su "Mapa de descampados de Amsterdam" (1999), una guía de terrenos vacíos de la ciudad. Almarcegui ha seguido realizando acciones que protegen el territorio no edificado a la vez que lo visibilizan, ejemplo de ello es "Un descampado" (2005-2006) (fig.8) que realizó en el Matadero de Arganzuela, Madrid. Almarcegui actualmente sigue creando proyectos bajo los conceptos de protección, resistencia al sobredesarrollo y antítesis de la evolución urbanística.

En 2009 crea la "Guía de descampados del valle del río Lea”(fig.9) donde localiza 12 terrenos vacíos esperando los Juegos Olímpicos de Londres 2012. Esta misma acción la repite en 2011 en el río Tévere, con los descampados en espera de las Olimpiadas del 2020 en Roma. Almarcegui en otras ocasiones ha conseguido preservar espacios silvestres de la ciudad durante años; son ejemplos “Un descampado" en Genk (2004-2014) o el más reciente en el Puerto de Rotterdam (2013-2018).

Con estas acciones el objetivo principal de Almarcegui no es de carácter medioambiental, sino mas bien simbólico. Su intención es visibilizar las lógicas corruptas de las políticas del sistema urbano pero, como efectos adversos, sus acciones consiguen preservar lugares dejando que esos espacios "vacíos" sigan llenos de vida silvestre, convirtiéndose en focos de aumento de la biodiversidad de la zona. Podríamos decir que estos lugares se autoexpresan, desapareciendo de este modo lo que se conoce como "artista" y lo que entiende como "arte", en cierto modo a los ojos del transeúnte pasan desapercibidas. Podría ser discutible este aspecto de la "no intervención", cuestionando, según el caso, hasta que punto ciertas zonas son interesantes para hacer este tipo de acciones de "preservación" o si por el contrario, dado su contexto, se pueden visionar como lugares idóneos para realizar proyectos que de alguna forma consciente activen al transeúnte. 


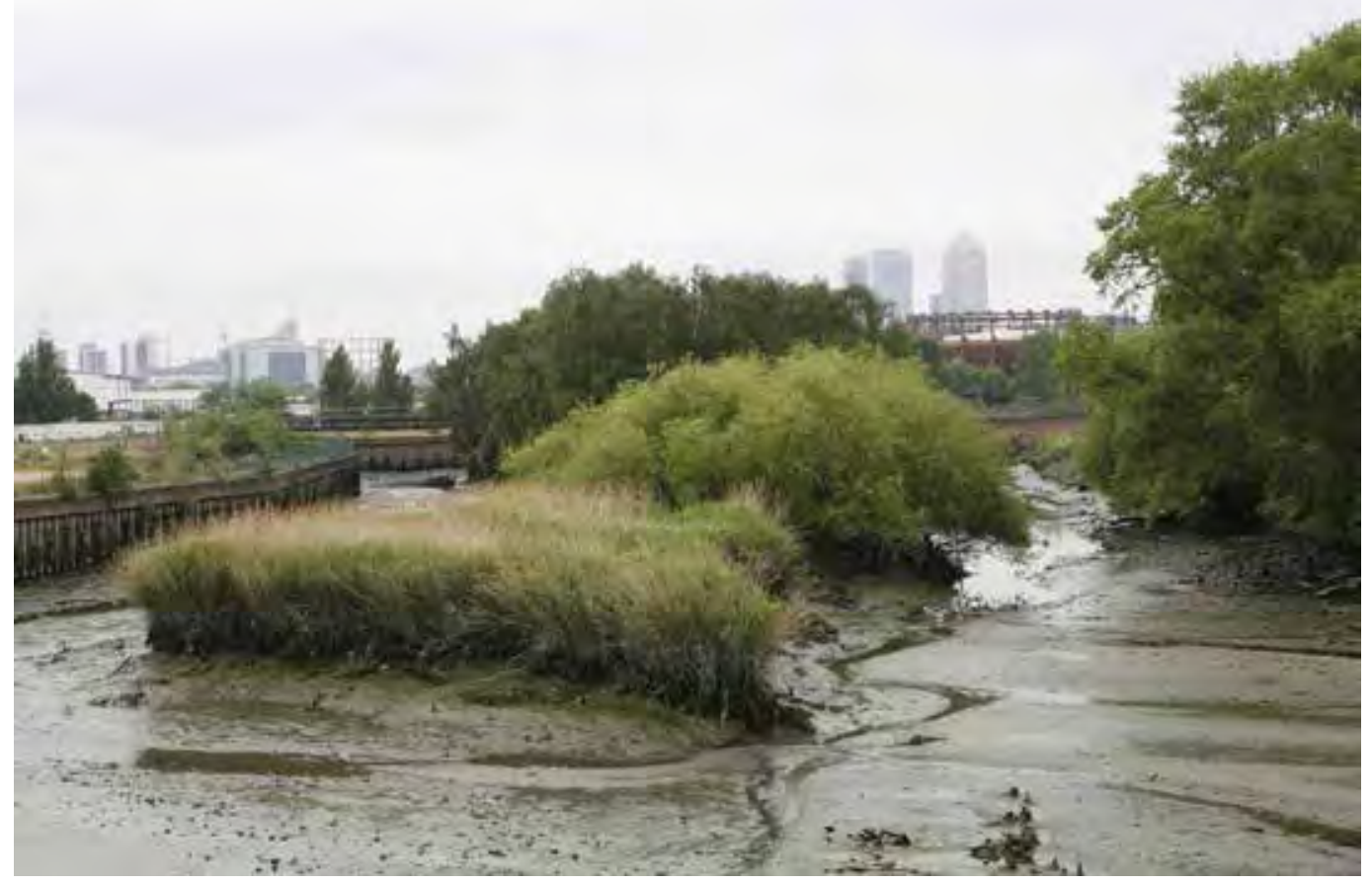

Figura 9: Lara Almarcegui, Guia de descampados del valle del Río Lea, 2009-2012: http://www. caac.es/prensa/img_alma11/frame.htm

Actualmente han aumentado las iniciativas artísticas y ecosociales que trabajan en esos lugares a los que Clèment llama "espacios de futuro" y que al parecer ya son presente. Tenemos la capacidad de florecer en estos lugares fértiles, en estos espacios de oportunidad para la creatividad y la resiliencia cultural. Con los ejemplos de ello podemos esclarecer que estamos germinado lentamente, creando una red de focos locales que poco a poco se expande en todas direcciones.

Se demuestra una vez mas, que desde el arte podemos adentrarnos en un mundo de pensamiento y creatividad, donde fundir nuestra mente con la materia y la energía en un empoderamiento de la consciencia del "yo ecológico". Nos aferramos a esa necesidad de proyección del interior como reflejo del exterior, a ese paraíso de horizontes infinitos, de experiencias y actitudes reveladoras, donde encontramos los orígenes primigenios del germen de un cambio. Un germen que contiene la energía para afrontar el mundo con nuevos puntos de vista capaces de unificar y equilibrar nuestra relación con la Naturaleza.

\section{Referencias}

Albelda, J. y Saborit, J. (1997) La construcción de la naturaleza. Valencia: Generalitat Valenciana.

Carandell, L., (2015): "Homenaje a Jericó” en Lápiz, n 288: 2015, pp. 29

Clément, G., (2007): Manifiesto del Tercer Paisaje. Barcelona: Gustavo Gili.

Iglesias, E., (2009): "La obra de Arne Ness, rica en elementos para la transformación cultural” en Revista el Ecologista, [En línea], nº 61, 2009: disponible en: http://www. ecologistasenaccion.org/article20342.html [Accesado el día 7 de agosto de 2016]

Goodall, J. (2007): "Lo que nos separa de los simios" en TEDglobal, Junio de 2007 
[En línea], disponible en: https://www.ted.com/talks/jane_goodall_at_ tedglobal_07?language=es [Accesado el día 5 de agosto de 2016]

Raquejo G. T., (2015): "La ficción en la construcción de la consciencia ecológica: correspondencias entre las dinámicas psíquicas y el planeta tierra" en Arte y Ecología Tonia Raquejo y José María Parreño (eds), Madrid, UNED. pp. 57-92.

Raquejo G. T., (2013): "Herencias del paisaje Pop. Marqueting y visión del territorio en el arte actual", en Goya, 343, 2013, pp. 166-181.

Riechmann, J., (2015): Autoconstrucción. La transformación cultural que necesitamos. Madrid: La Catarata.

Riechmann, J., (2005): “¿Cómo cambiar hacia sociedades sostenibles?. Reflexiones sobre biomímesis y autolimitación." en Isegoría, vol. 32, 2005, pp. 95-108.

Solà-Morales, I., (1996): "Presentes y futuros. La arquitectura en la ciudades". Barcelona, pp. $10-23$

Soler R. M. I. y Soto S. P. (2014): "Los latidos de la tierra. Arte ecológico para acompasar nuestros ritmos" en Arte y políticas de identidad, vol. 10, 2014, pp. 75-89. 